\title{
Gross Anatomy of the Celiac, Cranial Mesenteric and Caudal Mesenteric Arteries in Hooded Crow (Corvus cornix)
}

\section{Hassan, S. and El-Sayed A.K.}

Institutions: Department of Anatomy and Embryology, Faculty of Veterinary Medicine, Suez Canal University, Ismailia Egypt,

With 4 figures $\quad$ Received September, accepted for publication September 2018

\section{Abstract}

The Celiac artery in hooded crow originated from descending aorta. It gives off the proventricular artery, splenic arteries then terminated with the right and left celiac arteries. The right celiac artery detached the right hepatic, left hepatic, gastroduodenal and the right gastric arteries. The gastro duodenal artery supplies the pylorus and duodenum. The right gastric artery gives off the ventral proventricular, dorsal gastric and ventral gastric arteries. The dorsal and ventral gastric arteries supply the gizzard. The left celiac artery gives off the left gastric artery to gizzard, the jejunal branch, duodenal branch, and pancreatico-duodenal artery. The cranial mesenteric artery originated from the descending aorta then gives off the duodo-jejunal artery, ileal branches, jejunal arteries. the duodo-jejunal artery divided into duodenal and jejunal branches. The ileal branches are the dorsal and ventral ileal arteries. The caudal mesenteric artery arose from the descending aorta then divided into cranial and caudal branches. The cranial branch is distributed in the cranial part of rectum and cecum. The caudal branch supplies the caudal half of rectum, cloaca and cloacal bursa.

Keywords: celiac- cranial mesenteric-artery- crow

\section{Introduction}

The Hooded Crow (Corvuscornix) is an omnivorous bird species (Cocker et al., 2005). It is an opportunistic predator and scavenger has a wide range of food including grain, small mammals, carrion and rubbish (Coombs, 1978; Yom-Tov, 1974). It is a major predator of bird's eggs and young (Mehlum, 1991; Luginbuhl et al., 2001and Sullivan and Dinsmore, 
1990). The hooded crow is distributed locally in Nile Delta and valley (Mahmoud, 1997). Recent increasing usage of different avian species rather than domestic chicken as models for biological research leads the anatomists to focus their studies on the morphology of these species (Baumel,et al, 1993; Dyce et al.,1996 and McLelland, 1990). Some studies were carried out on the celiac artery of birds like Khalifa (2014). This study aimed to augmenting the know-ledge on the gross morphology of arterial supply of viscera in the hooded crow in particular and to compare it with other birds. Therefore, the findings of this study might have a valuable contribution to the avian anatomy and surgery.

\section{Material and methods}

The present study was carried out on eight adult apparently healthy hooded crows of both sexes obtained from farms in Ismaillia. Each bird was anaesthetized by IM injection of $0.5 \mathrm{cc}$ of $2 \%$ xylazine $\mathrm{Hcl}$ $(3 \mathrm{mg} / \mathrm{kg})$ followed by injection of heparin (Cal Heparin 5000 I.U.) in the wing vein to prevent blood clotting then the bird was exsanguinated through the common carotid artery. The abdomen then was opened and the viscera were displaced to see the descending aorta. The descending aorta then was cannulated and flushed with normal saline then was injected with gum milk latex coloured with red Rotring ink (Tompsett and Wakelly, 1965). The whole birds then were immersed in a mixture of $10 \%$ formalin and $2 \%$ phenol and $1 \%$ glycrinn and were left to $2-3$ days in room temperature. The celiac, cranial mesenteric and caudal mesenteric arteries were then dissected. The observations were photographed with Sony digital camera 10 $\mathrm{mp}$. The nomenclature was adopted to the Nomina Anatomica Avium (Baumel et al., 1993)

\section{Results \\ Celiac artery}

It originates from ventral aspect of the descending aorta (Fig 1) under the level of $4^{\text {th }}$ thoracic vertebra, between spleen, lung and right lobe of the liver. It continues between spleen, proventriculus and right lobe of liver till reaching the junction between the gizzard and proventriculis to terminate by two terminal branches; right and left celiac arteries. It detaches proventricular and splenic arteries before its termination.

The proventricular artery (Fig 1) arises from the cranial aspect of celiac artery. Just below its origin it gives off esophageal branch to the end part of esophagus and two to four small proventricular twigs, then it continues as dorsal gastric artery 
which gives off small fine branch to the proventriculus then it proceeds to end in the gizzard.

The splenic arteries (Fig 2) are 8-9 fine arteries arise from the cranial aspect of celiac artery. The $1^{\text {st }}$ branch originated half $\mathrm{cm}$ under the origin of proventricular artery while the last branch arises half $\mathrm{cm}$ under the origin of hepatic artery

The right celiac artery (Fig3) dips between the junction of the proventriculus and gizzard and right lobe of liver then it is directly broken down into five branches $3 \mathrm{~mm}$ distal to its origin; right hepatic, left hepatic, gastroduodenal and right gastric arteries. The right hepatic arteries are two branches(Fig3) supply the right lobe of the liver. The left hepaticartery (Fig 3 ) supplies the left lobe of the liver. The gastroduodenal artery (Fig 3 ) supplies the pylorus and $1^{\text {st }}$ part of duodenum. The right gastric artery (Fig 3) gives off three branches: ventral proventricular artery to the right and ventral surfaces of the proventriculus, dorsal gastric artery to the craniodorsal sac of the gizzard and ventral gastric artery to the caudo-ventral sac and cranioventral muscle of the gizzard.

The left celiac artery (Fig 2) courses between the right side of the caudal pole of the spleen and the left side of right lobe of liver and gall bladder then passes caudo-ventrally between jejunum, duodenum and pancreas till reaching above the flexure between the ascending and descending duodenum to be continued as pancreatico-duodenal artery. It breaks down into four branches; left gastric, jejunal, duodenal and pancreatico-dudenal arteries. The left gastric artery (Fig 2) supplies the caudoventral and dorsolateral muscles of the gizzard. The jejunal branch (Fig 2) to the jejunum. The duodenal branch (Fig 2) supplies the duodenum. The pancreaticoduodenal artery (Fig2) vascularizes the duodenum and pancreas.

cranial mesenteric artery (Fig 4) It is originated from the ventral aspect of descending aorta under the $6^{\text {th }}$ thoracic vertebra. It then directscaudoventrally between ilium on left side, duodenojejunal flexure on right side and kidney dorsally. It proceeds in the same direction to be terminated in the center of jejunal loop by the jejunal branches. It gives off duodeo-jejunal and ileal arteries before its termination.

The duodeno-jejunal artery (Fig. 4) arises from the caudal aspect of the cranial mesenteric artery medial to the duodeno-jejunalflexure then directly divides into duodenal and jejunal branches. The duodenal branch (Fig 4) supplies the proximal part of ascending loop of duodenum then 
anastomoses with duodenal branch of left celiac artery. The jejunal branch (Fig 4) vascularises the $1^{\text {st }}$ small part of jejunum and anastomoses with the $1^{\text {stjejunal artery. }}$

The ileal branches (Fig 4) are two branches; dorsal and ventral ileal arteries. The dorsal ileal artery(Fig4) arises from the cranial aspect of cranial mesenteric artery at the level of duodeno-jejunal artery and directs cranially to supply the most caudal part of the ileum. It then anastomoses with the cranial branch of caudal mesenteric artery. The ventral ileal artery(Fig4) arises from the cranial aspect of cranial mesenteric artery about half $\mathrm{cm}$ ventral to the dorsal ileal artery. It directs caudally to be distributed in the cranial part of ileum and the most caudal part of jejunum. It anastomoses with the last jejunal artery.

The jejunal arteries(Fig4) are about 15-20 branches and are considered as the terminal branches of cranial mesenteric artery. They descend ventrally in the mesojejunum until reaching the mesenteric border of jejunum sending cranial and caudal branches. The cranial branch of each jejunal artery joins the caudal branch of the preceding one to form arterial arches from which numerous fine branches detach running on each side of jejunum until reaching its free border.
Caudal mesenteric artery (Fig 4) It arises from the ventral aspect of the descending aorta at the level of the caudal end of sacrum. It then descends ventrally caudal to the caudal division of kidney and extends for about $1 \mathrm{~cm}$ in the mesorectum to be terminated by cranial and caudal branches.

The Cranial branch (Fig 4) passes cranially on the mesenteric border of the rectum, sending two branches to its both sides. The caudal one distributes in the wall of cranial part of rectum while the cranial one distributes in the wall of most cranial part of the rectum, then extends to supply cecum. The caudal branch(Fig4) directs caudally on the mesenteric border of rectum then detaches branches to the its caudal half, cloaca and cloacal bursa.

\section{Discussion}

The celiac artery in hooded crow is the $1^{\text {st }}$ visceral branch of the descending aorta like that were recorded by Khalifa (2014) in cattle egret and Kuru (2010); Kutul (2002); Aslan and Takci (1998); Silva et al., (1997); Fowler (1991); King and McLelland (1984) and Lauper et al., (1975) in domestic birds.

The celiac artery in crow originates from ventral aspect of descending aorta like that were recorded in domestic fowl by Kuru (2010), Kurtul 
and Dursun (2002), Franz and Salomon (1993), Miladinovic et al. (1986), King and McLelland (1984), Lauper et al. (1975) whileKhalifa (2014) in cattle egret, Silva et al. (2005) in chicken, Duzler et al. (2011) in quail, Ragab et al. (2013) in goose. On other hand, Alan et al. (2016) in flamingos stated that the celiac artery originates from the right surface of the descending aorta.

The celiac artery in crow is detached from the descending aorta under the level of 4th thoracic vertebra similar to Khalifa (2014) in cattle egret while, Haligur and Duzler (2010) reported that, the celiac artery arises at the level of the 2-3 ribs. On the other hand, (Kuru, 2010), 2002; Dursun, 2002; Franz and Salomon, 1993; Miladinovic et al., 1986; King and McLelland, 1984; Lauper et al., 1975) mentioned its origin at the 5th - 6th thoracic vertebra in domestic fowl. It originates at the level of the third/fourth thoracic intervertebral junction and the fourth pair of costae in flamingo (Alan et al., 2016)

The celiac artery in hooded crow supplies the end part of esophagus, proventriculus, spleen, liver, gizzard, duodenum and pancreas. These findings were in accordance with Khalifa (2014) in cattle egret and (Kuru,2010; Kutul, 2002; Aslan and Takci, 1998; Silva et al., 1997;
Fowler, 1991; King and McLelland, 1984 and Lauper et al., 1975) in domestic fowl but these authors mentioned that celiac artery supplied part from ileum in contrary with the present study in addition to that the current work found that the celiac artery detaches esophageal branch that did not recorded by the previous authors.

The $1^{\text {st }}$ branch of celiac artery in crow is proventricular artery similar results reportedby Kurtul and Haziroglu (2002), Silva et al. (1997) in rooster, drake, pigeons and geese, Haligur and Duzler (2010) in red falcons and Alan et al. (2016) in flamingo but Kuru (2010) in domestic fowls; Aycan and Duzler (2000) in eagle owl; McLeod et al.(1964) in domestic fowls, Malinovsky (1965) in buzzard, Nickel et al.(1977) in domestic Fowls stated that the first branch from the celiac artery is the esophageal artery. The esophageal artery in crow in the present study originated from the dorsal porventricular artery while Alan et al. (2016) did not record it in flamingo. On the other hand, Duzler et al. (2011) in Japanese quail, Vasconcelos et al. (2012) in ostrich mentioned that the esophageal artery and dorsal proventricular artery originate from the celiac artery with a common trunk.

The splenic arteries originate from the celiac artery or dorsal proventricular artery or left celiac or right celiac 
(Malinovsky and Novotna, 1977; Silva et al., 1997; Pinto et al., 1998; Aslan and Takci, 1998; Haligur and Duzler, 2010 and Kuru 2010 in domestic fowl; Duzler et al., 2011 in Japanese quail; Goncalves et al., 2011 in blue-fronted amazon; Geeverghese et al. 2012; Vasconcelos et al. 2012 in ostrich; Ragab et al. 2013 in the domestic goose; and Khalifa, 2014 in the domestic goose). The present study showed that the splenic arteries come directly from celiac artery except the $1^{\text {st }}$ branch which originated from the dorsal proventricular artery and the last branch from the hepatic artery. In flamingos, three splenic arteries arise directly from the celiac artery, and the fourth originates from right celiac artery Alan et al. (2016).

The celiac artery in crow bifurcates into right and left celiac arteries similar to that reported by Malinovsky and Novotna (1977) in domestic fowl; Pinto et al. (1998) in domestic duck; Kurtuland Haziroglum (2004) in rooster, drake, and pigeon; Silva et al. (2005) in female fowls; Kuru (2010) in domestic fowl; Haligur and Duzler (2010) in red falcon; Geeverghese et al. (2012) in domestic pigeons; Vasconcelos et al. (2012) in ostrich. On other hand Chiasson (1982) in pigeon and Aycan and Duzler (2000) in eagle owl did not report that bifurcation.
The right celiac artery detaches right hepatic arteries, gastrodudenal, and right gastric artery. Khalifa (2014) in cattle egret reported that it gave off the ileocecal, gastroduodenal, right gastric arteries and pancreaticoduodenal artery. Kuru (2010) in domestic fowl, Aslan and Takci (1998) in geese, Silva et al (1997), Franz and Salomon (1993) and Baumel (1975) in domestic fowl added that, the splenic arteries, right hepatic artery, ileal arteries also originated from the right branch of the celiac artery.

The left branch of the celiac artery in crow gives off left gastric artery, duodenal branch, jejunal branch and pancreatico-duodenal artery. Khalifa (2014) in cattle egret and Kuru (2010), Haligur and Duzler (2010) and Getty (1975) in domestic fowl reported that it detaches ventral proventricular artery, ventral gastric artery and left gastric artery, that in agreement with Kuru (2010); Haligur, Duzler, (2010), Getty (1975) in domestic fowl and Khalifa (2014) in cattle egret reported that, the left branch of the celiac artery gives off the right hepatic artery.

In agreement with Farag et al. (2013) in turkey, Nickel et al., (1977) and Campos et al. (2006) in the fowl and Pinto et al. (1998) in the domestic duck, the cranial mesenteric artery in crow originates just caudal to the origin of celiac artery. 
In hooded crow, the cranial mesenteric artery branches into duodnojujenal, ileal and jujenal arteries like that recorded by Farag et al. (2013) in turkey. Nickel et al. (1977) in fowl mentioned that the first vessel arising from the cranial mesenteric artery is the $A$. ileocecalis then continues as the truncus jejunalis. Pinto et al. (1998) in the domestic duck described the cranial mesenteric artery as dividing into three branches, the first to colorectum, the second that givesthe jejunal arteriesand the third to right cecum and ileum.

The ileal branches in hooded crow are two branches; dorsal and ventral ileal arteries. thereare 6 ileal arteries in turkey (Farag et al., 2013), 1-4 in the fowl (Santana et al.,2001), 5-13 in bumpkin chickens (Cardoso et al., 2002).

The colic branch of the cranial mesenteric artery or ileocecal artery that observed by Farag et al. (2013) in turkey did not observed in or in any available literatures except Ebada et al. (2006) in the ostrich who's recorded a proper colic artery arising from the cranial mesenteric artery.

The Caudal mesenteric artery in hooded crow arises from the ventral aspect of the descending aorta dividing into cranial and caudal branches. Similar results were reported by Pinto et al. (1998) in the domestic duck, Santana et al. (2001) and
Campos et al. (2006) in the fowl while, Ebada et al. (2006) in the ostrich mentioned that the caudal mesenteric artery gives off 10-12 long branches.

\section{References}

Alan, A.; Duzler, A.; Orhan,I. (2016): Ramification of the celiac artery in the greater flamingo (Phoenicopterusro-seus). Veterinarni Medicina, 61, 2016 (2): 97-101

Aslan, K. and Takci, I. (1998): The arterial vascularization of the organs (stomach, intestine, spleen, kidneys, testes and ovarium) in the abdominal region of the geese obtained from Kars surrounding (in Turkish). Kafkas University, Fac. Vet. Med. J., 4: 49-53.

Aycan, K. and Duzler, A. (2000): The anatomy of celiac artery in the eagle owl (Bubo bubo) (in Turkish). Ankara University, Fac. Vet. Med. J., 47: 319-323.

Baumel, J. J. (1975): Aves Heart and Blood Vessels. In, Sisson and Grossman's the Anatomy of the Domestic Animals. Getty R (Eds.), Vol II, 5 th ed. Saunders Company, Philadelphia, 1990-1991.

Baumel, J. J.; King, A.S.; Breazile, J. E.; Evans, H. E.; Vanden Berge, 
J. C. (1993): Nomina Anatomica Avium. Published by The Nuttall Ornithological Club. No: 23, Cambridge, Massachusetts.

Campos, D.B.; Silva, F.O.C.; Severino, R.S.; Drummond, S.S.; De Lima, E.M.M.; Santana, M.I.S.; and Bombonato, P.P. (2006): Artériasmesentéricas cranial e caudal emaves (Gallus gallus) da linhagem Cobb 500.Braz. J. vet. Res. anim. Sci., São Paulo, v. 43, n. 3, p. 289295.

Cardoso, J.R.; Martins, A.K.; Queiroz, D.N.; Drummond, S.S.; Mota, F.C.D.; Servino, R.S.; Silva, F.O.C.; and Santos, A.L.Q. (2002): Origin and aspects of ramification of the cranial and caudal mesenteric arteries in bumpkin chickens. Bioscience Journal vol. 18(1) p. 151- 160.

Chiasson, R.B. (1982): Laboratory Anatomy of the Pigeon. Brown Company Publishers, lowa.

Cocker, M. and Mabey, R. (2005): Birds Britannica. London: Chatto \& Windus. pp. 418-425. ISBN 0-70116907-9.

Coombs, F. (1978): The crows: a study of the corvids of Europe, Batsford.
Dursun, N. (2002): Anatomy of Domestic Birds (in Turkish). Medisan Publishing, Ankara, pp. 140-141.

Duzler, A.; Nur, I.H.; Alan, A. (2011): A macroanatomical study on ramification and course of aorta descendens in Japanese Quail. Journal of Faculty of Veterinary Medicine Erciyes University 8, 139-152.

Dyce, K. M.; Sack, W. O.; Wensing, C. J. (1996): Avian Anatomy. pp. 824-828. In: Textbook of Veterinary Anatomy, 2nd ed. W.B. Saunders, Philadelphia.

Ebada, s.; Mohamed, El-Baz, A.M. Shoaib, M.B. and Sayed, A.A. (2006): Morphological study on the colon of the ostrich (Struthiocamellus). Kafr El-Sheikh Vet. Med. J. Vol. 4 No. 1(977-999).

Farag, F.M.M.; Tolba, A.R. and Daghash, S.M. (2013): The Arterial Supply of the Intestinal Tract of the Domestic Turkey Fowl (Meleagris gallopavo). J. Vet. Anat. Vol 6 No 1, (2013) $53-68$

Fowler, M. E. (1991): Comparative clinical anatomy of ratites. J. Zool. Wild. Med., 22: 204-227.

Franz, V. and Salomon, V. (1993): Lehrbuch der Geflügelanatomie. 
Gustav Fischer Verlag, Jena, Suttgart.

Geeverghese, C,; Barbosa, A.C.O.; Lemos, M.S.; Borges, G.B.O.; Santana, M.I.; Lima, E.M.M. (2012): Description of the celiac artery in domestic pigeons (Columba livia) (in Portuguese). Biotemas $25,125-131$.

Getty, R. (1975): The Anatomy of the Domestic Animals. 5th ed. WB Saunders Company, New York.1990-1991.

Goncalves, E.S.; Santana, M.I.; Zancan, F.T.; Pinto, A.B.F.; Lima, E.M.M. (2011): Configured distribution of the celiac artery in bluefronted amazon (Amazona aestiva) (in Portuguese). Arquivo Brasileiro de Medicina Veterinaria e Zootecnia 63 1141-1148.

Haligur, A. and Duzler, A. (2010): Course and branch of the celiac artery in the red falcon (Buteo rufinus). Vet. Med., 55(2): 79-86.

Khalifa, E. F. (2014): gross anatomical studies on the celiac artery in cattle egret (Bubulcus ibis) with special reference to the arterial supply of the stomach. J. Vet. Anat., 7(1), pp:1-13
King, A. S. and McLelland, J. (1984): Birds, Their Structure and Function. $2^{\text {nd }}$ ed., Bailliere Tindall, England.

Kurtul, I. (2002): Comparative macro-anatomical investigations on the pattern and branches of the aorta descendens among the rooster, drake, and pigeon (in Turkish). [PhD thesis.] Fac. Vet. Med. Ankara Univ., pp. 24-37.

Kurtul, I.; Haziroglum R.M. (2004): Comparative macro-anatomical investigations on the pattern and branches of the descending aorta among the rooster, drake, and pigeon (in Turkish). Veterinary Journal of Ankara University 51, 1-6.

Kuru, N. (2010): Macroanatomic investigations on the course and distribution of the celiac artery in domestic fowl (Gallus gallus domesticus). Scientific Research and Essays 5, 3585-3591.

Lauper, N. T.; Unni, K. K.; Kottke, B. A. and Titus, K. L. (1975): Anatomy and histology of aorta of White Carneau pigeon. Lab. Invest., 32: 536-551.

Luginbuhl, J. M.; Marzluff, J. M.; Bradley, J. E.; Rabhael, M. G. and Varland, D. E. (2001): Corvid survey 
techniques and the relationship between corvid relative abundance and nest predation. -Journal of Field Ornithology, 72: 556- 572.

Malinovsky, L.; Novotna, M. (1977): Branching of the celiac artery in some domestic birds, III. A comparison of the pattern of the coeliac artery in three breeds of the domestic fowl (Gallus gallus $f$. domestica). Anatomischer Anzeiger 41, 137146.

McLelland, J. (1975): Avis cardiovascular system in king and McLelland, Vol. I. 5th ED. London, New York, Toronto, Sydney, San Francisco.

McLelland, J. (1984): Avis cardiovascular system in king and McLelland, Vol. I. 5th ED. London, New York, Toronto, Sydney, San Francisco.

McLelland, J. (1979): Avis cardiovascular system in Sisson and Grossman's "the anatomy of the domestic animals" Getty, R. Vol. II. 5th. Philadelphia, Saunders, London, Toronto.

McLelland, J (1990): A. Colour Atlas of Avian Anatomy. Wolfe Publishing Ltd. England.

J. Vet. Anat.
Mahmoud, E. T. (1997): Birds known to occur in Egypt. Vol (8). Cabinet of ministers. Egyptian Environmental Affairs Agency (EEAA). Dept. of nature protection. Publication of national biodiversity unit.

Mehlum, F. (1991): Egg predation in a breeding colony of the Common Eider Somateria mollissima in Kongsfjorden, Svalbard. -Skrifter- Norsk Polar institutt: 37-45.

Miladinovic, Z.; Popoic, S.; and Jojic, D. (1986): Vascularization of the glandular stomach of the hen (Gallus domesticus). Acta Vet., 5(6): 335-342.

Nickel, R.; Schummer, A.; and Seiferle, E. (1977): Anatomy of the Domestic Birds. Verlag Paul Parey, Berlin.

Pinto, M.R.A.; Ribeiro, A.A.C.M.; Souza, W.M. (1998): The arrangements configured by the coeliac artery in the domestic duck (Cairina moschata) (in Portuguese). Brazilian Journal of Veterinary Research and Animal Science 35, 103-106

Ragab, S.A.; Farag, F.M.M.;Tolba, A.R.; Saleh, A.A.; El-Karmoty, A.F. (2013): Anatomical study on the celiac artery in the domestic goose (Anseranse rdomesticus) with special reference to the arterial supply of the stomach. Journal of Veterinary Anatomy $6,23-40$. 
Santana, M. I. S.; Carneiro E. Silva, F. O.; Severino, R. S.; Santos, A. L. Q.; rummond, S. S.; Bombonato, P. P.(2001) :Vascularização arterial da bolsacloacalem Gallus gallus domesticus( matrizesdecorte Avian Farms). Brazilian Journal of Veterinary Research and Animal Science, v. 37, n. 2.

Silva Carneiro, F. O.; Severino, R. S.; Santos A.L.Q.; Drummond, S. S.; Bombonato, P. P.; Santana, M.I.S.; Lopes, D. and Marçal, A. V. (1997): Origin and distribution of the artery celiacae in birds (Gallus gallusdomesticus-Ross linage). Revista da FZVA,4 (1): 64-76.

Silva, F.O.C. Severino, R.S.; Drummond, S.S.; Bombonato, P.P.; Campos, D.B.; Campos, A.B.; Lima, E.M.M.; Borges, A.C.; Mar- celino, E.L. (2005): Origin, ramifications and distributions of the celiac artery in female fowls (Gallus gallus) From Cobb 500 Lineage (in Portuguese). Bioscience Journal 21, 149154.

Sullivan, B. D. and Dinsmore, J. J. (1990): Factors affecting egg predation by American crows. -Journal of Wildlife Management, 54: 433-437.

Tomsett, D. H. and C. W. Wakeley (1965): Anatomical Techniques. 1st Edition. E \& Living Stone Ltd. Edinburgh and London

Vasconcelos B.G.; Silva, F.O.C.; Miranda, R.L.; Pereira, C.C.H.; Santos, A.C.; Miglino, M.A. (2012): Origin and distribution of the celiac artery in ostrich (Struthio camelus) (in Portuguese). Ciencia Animal Brasileira 13, 108-114. 


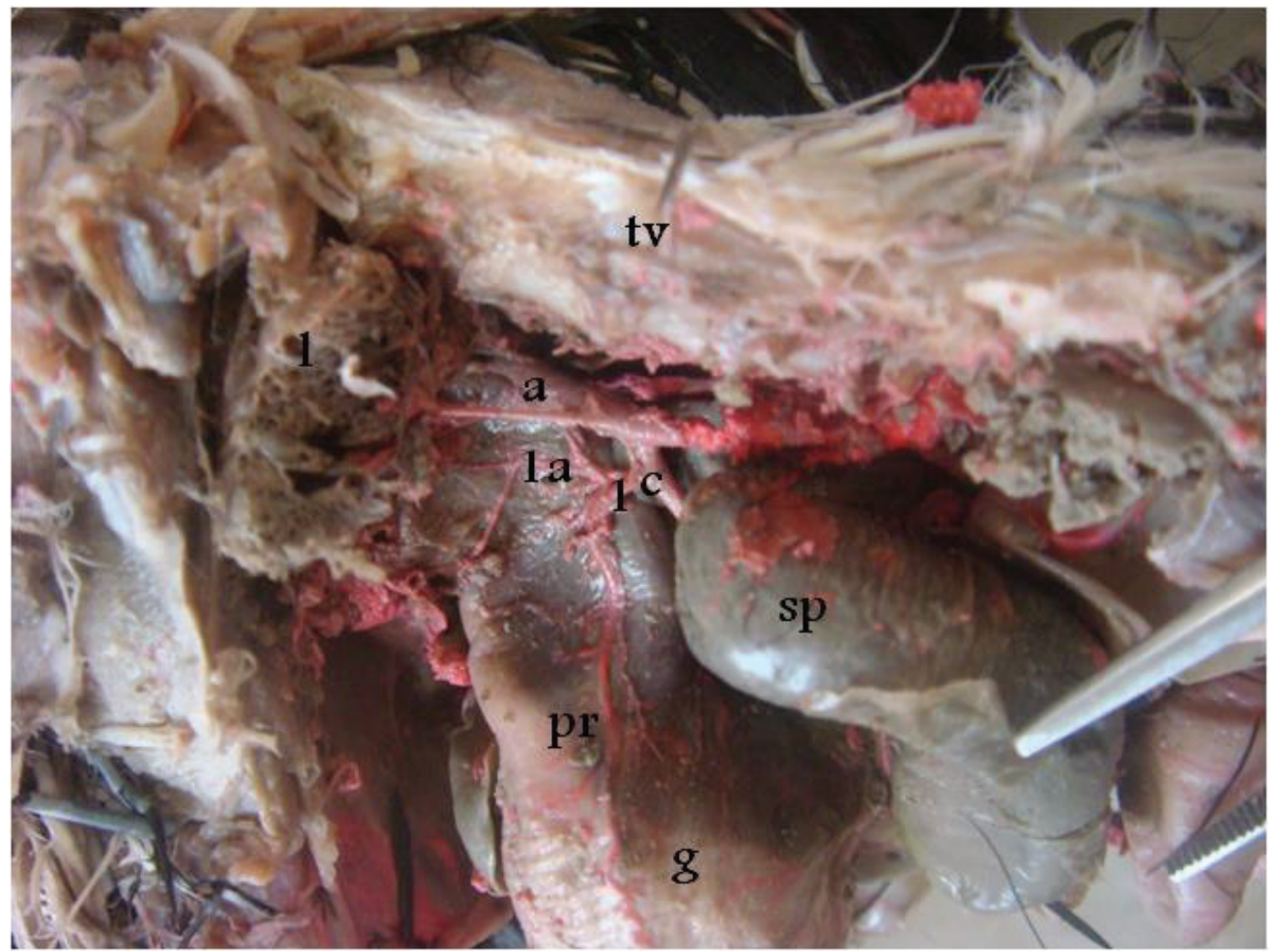

Fig (1): a photograph of opened abdomen of hooded crow showing; a) Aorta, c) celiac, 1) proventricular artery, 1a) oesophageal branch, sp) spleen, pr) proventriculus, g) gizzard, tv) thoracic vertebrae, I ) lung 


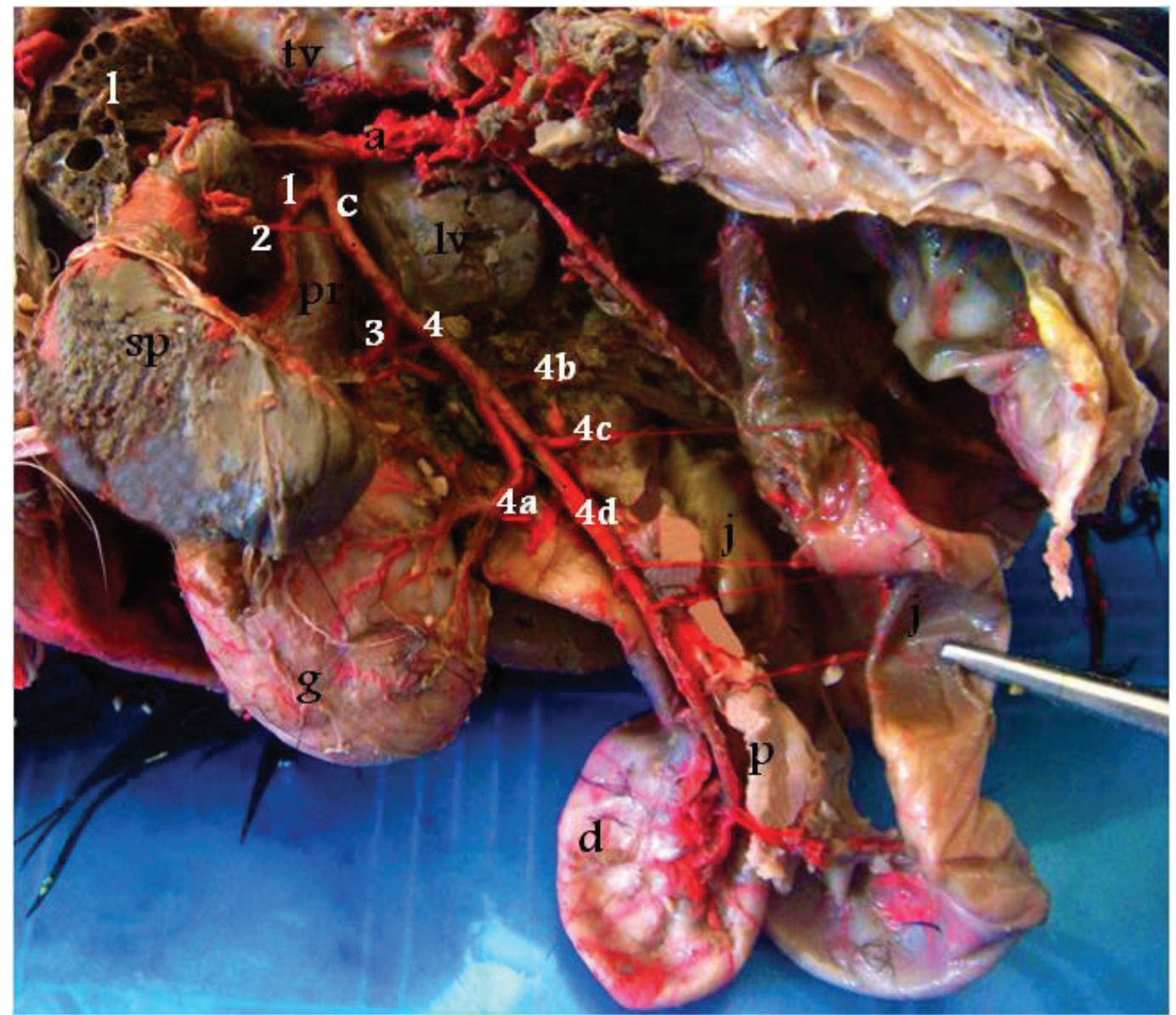

Fig (2): a photograph of viscera of hooded crow showing; a) aorta, c) celiac,1) proventricular artery, 2) splenic,3) right ciliac,4) left ciliac, 4) aleft gastric,4b) duodenal,4c) jejunal, 4d) pancreaticodudenal, I ) lung, Iv) liver,sp) spleen, d) duodenum, j) jejunum, p) pancreas, tv) thoracic vertebrae, pr) proventriculus, g) gizzard. 


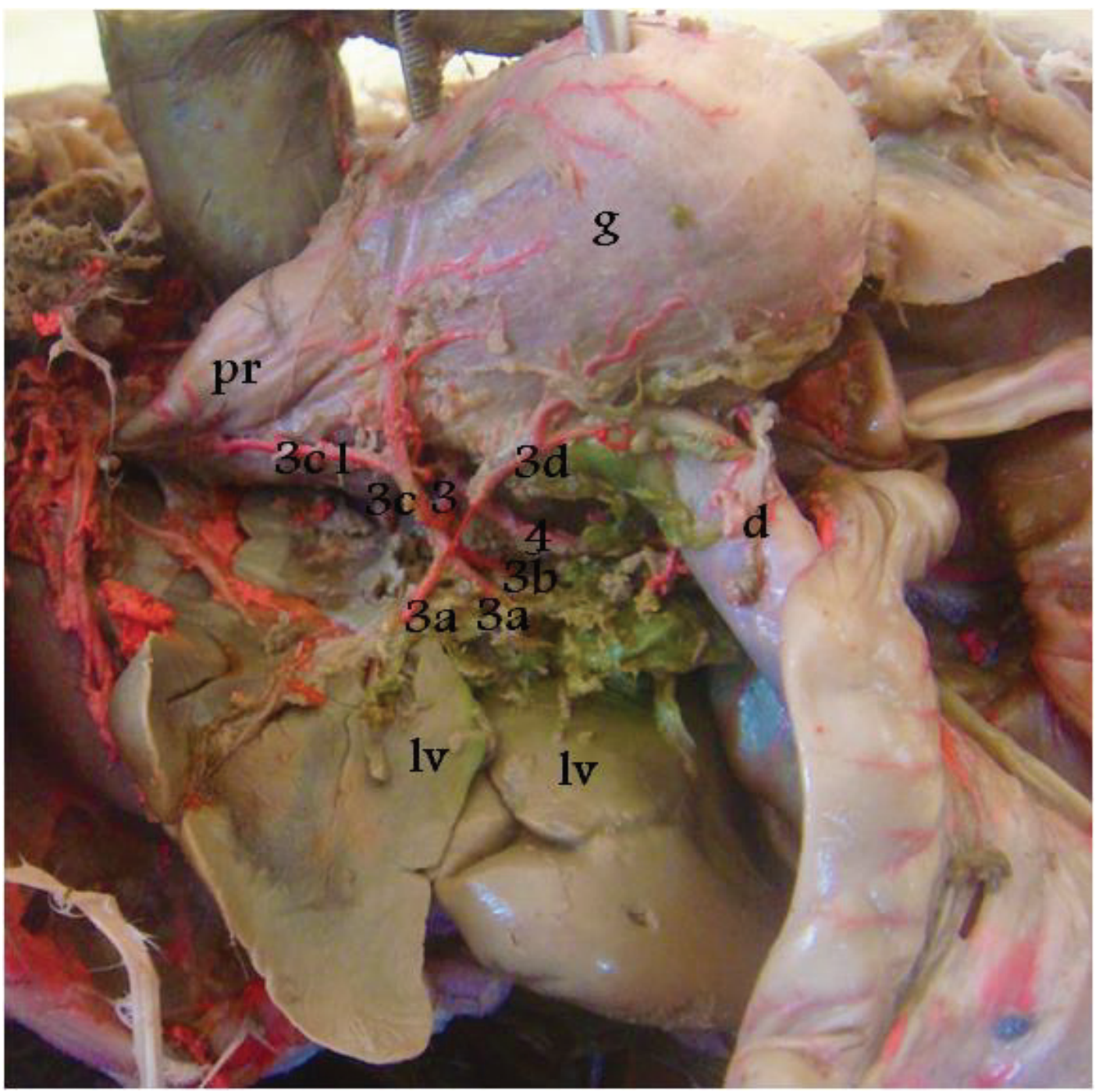

Fig (3): a photograph of opened abdomen of hooded crow showing; 3) right celiac, 4) left celiac, 3a) right hepatic, 3b) left hepatic, 3c) right gastric, 3c1) proventricular branch, prproventriculus, g) gizzard, d) duodenum, Iv) liver. 


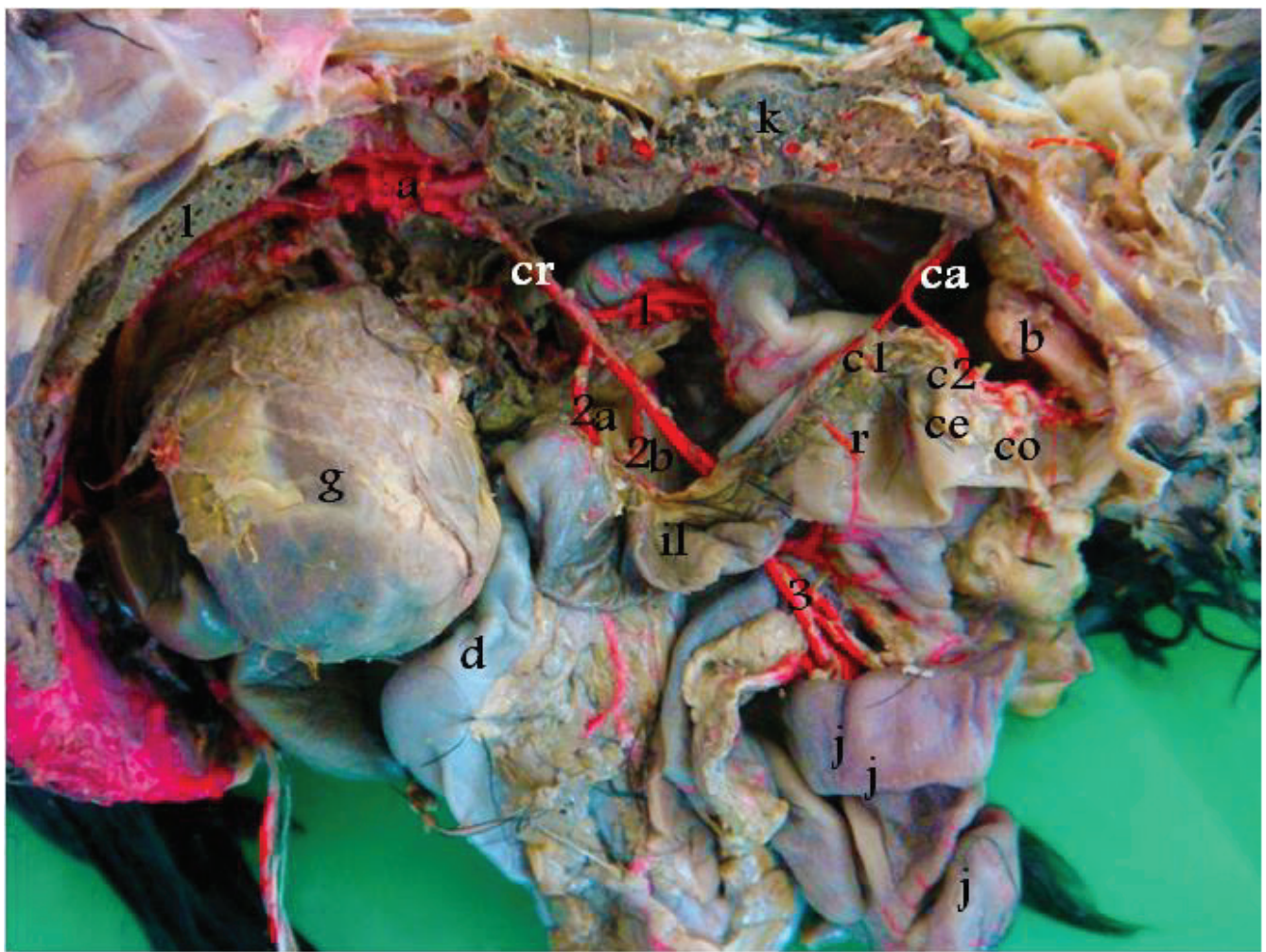

Fig (4):a photograph of viscera of hooded crow showing, a) Aorta, cr) cranial mesentric artery, ca) caudal mesenteric, 1) duodinojejunal artery, 2a) dorsal ilial artery,2b) ventral ileal artery, 3) jejuna arteries, c1) cranial branch, c2) caudal branch,g gizzard, d) duodenum,j) jejunum,il) ileum, ce) cecum, r) rectum, co) cloaca, b) cloacal bursa, k) kidney, I) lung. 


\section{Animal species in this Issue}

\section{Hooded Crow (Corvus cornix)}

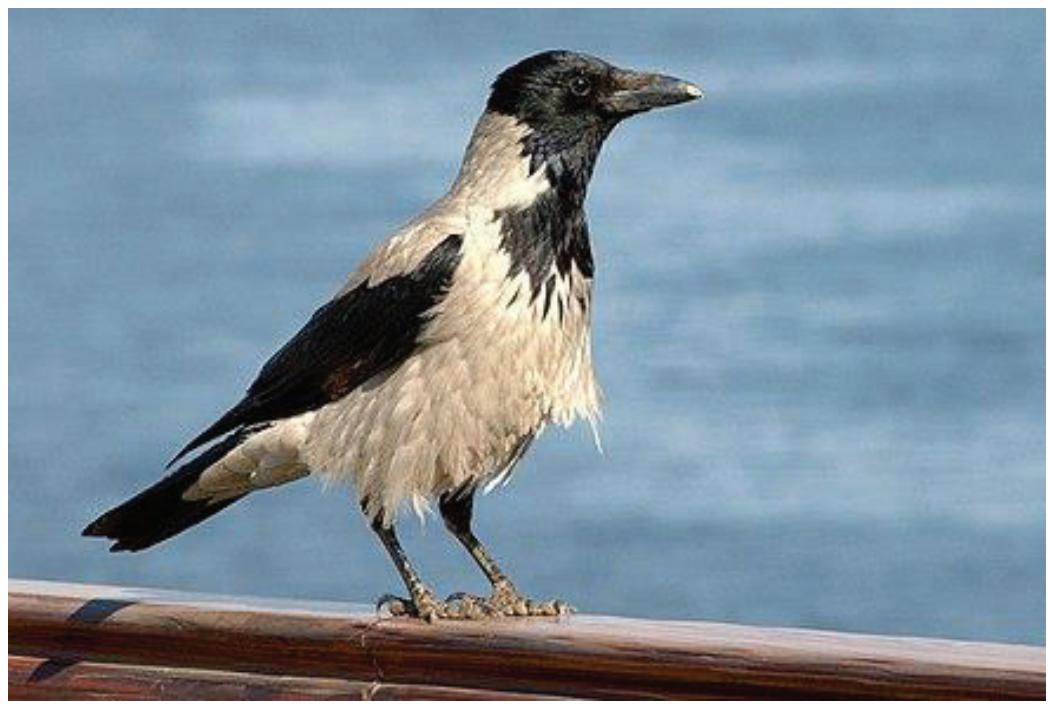

Kingdom: Animalia \& Phylum: Chordata \& Class: Aves \& Order: Passeriformes \& Family: Corvus \& Genus: Corves \& Species: C. cornix

Except for the head, throat, wings, tail, and thigh feathers, which are black and mostly glossy, the plumage is ash-grey, the dark shafts giving it a streaky appearance. The bill and legs are black; the iris dark brown. Only one moult occurs, in autumn, as in other crow species. The male is the larger bird, otherwise the sexes are alike. Their flight is slow and heavy and usually straight. Their length varies from 48 to $52 \mathrm{~cm}$ (19 to 20 in). When first hatched, the young are much blacker than the parents. Juveniles have duller plumage with bluish or greyish eyes and initially a red mouth. Wingspan is $98 \mathrm{~cm}$ (39 in) and weight is on average $510 \mathrm{~g}$.

The hooded crow, with its contrasted greys and blacks, cannot be confused with either the carrion crow or rook, but the kraa (help·info) call notes of the two are almost indistinguishable.

Source: Wikipedia, the free encyclopaedia 